\title{
Sustained response of three pediatric BRAFV600E mutated high- grade gliomas to combined BRAF and MEK inhibitor therapy
}

\author{
Stephanie A. Toll ${ }^{1,2, *}$, Hung N. Tran ${ }^{3, *}$, Jennifer Cotter ${ }^{2,4}$, Alexander R. Judkins ${ }^{2,4}$, \\ Benita Tamrazi ${ }^{2,5}$, Jaclyn A. Biegel ${ }^{2,4}$, Girish Dhall ${ }^{1,2}$, Nathan J. Robison ${ }^{1,2}$, Kaaren \\ Waters $^{1}$, Palak Patel ${ }^{2}$, Robert Cooper ${ }^{3, *}$ and Ashley S. Margol, ${ }^{1,2, *}$ \\ ${ }^{1}$ Division of Hematology, Oncology and Blood and Marrow Transplantation, Children's Center for Cancer and Blood Diseases, \\ Children's Hospital Los Angeles, Los Angeles, CA, USA \\ ${ }^{2}$ University of Southern California Keck School of Medicine, Los Angeles, CA, USA \\ ${ }^{3}$ Kaiser Permanente Southern California, Los Angeles, CA, USA \\ ${ }^{4}$ Department of Pathology and Laboratory Medicine, Children's Hospital Los Angeles, Los Angeles, CA, USA \\ ${ }^{5}$ Department of Radiology and Imaging, Children's Hospital Los Angeles, Los Angeles, CA, USA \\ *These authors contributed equally to this work \\ Correspondence to: Stephanie A. Toll, email: stoll@chla.usc.edu \\ Keywords: high-grade glioma; BRAF mutation; targeted therapy; pediatrics
}

Received: October 27, $2018 \quad$ Accepted: December 27, $2018 \quad$ Published: January 11, 2019

Copyright: Toll et al. This is an open-access article distributed under the terms of the Creative Commons Attribution License 3.0 (CC BY 3.0), which permits unrestricted use, distribution, and reproduction in any medium, provided the original author and source are credited.

\section{ABSTRACT}

Outcomes for children with high-grade gliomas (HGG) remain dismal despite aggressive treatment strategies. The use of targeted therapy for BRAF ${ }^{\mathrm{V} 600}$ mutated malignancies including HGG is being explored as a potentially well tolerated and effective therapeutic option. The results of adult melanoma studies demonstrating that combination therapy with BRAF inhibitors and MEK inhibitors results in prolonged survival led us to employ this treatment strategy in children with BRAF ${ }^{\mathrm{V} 600}$ mutated HGG. In this case series, we describe three pediatric patients with HGG with confirmed BRAF ${ }^{\mathrm{V} 600 E}$ mutation who demonstrated responses to combination therapy with dabrafenib and trametinib.

\section{INTRODUCTION}

Astrocytoma is the most common brain tumor in children, with high-grade gliomas (HGG) comprising 11\% of all pediatric brain tumors [1]. Survival rates for children with HGG are poor, with 3-year overall survival (OS) of $22 \pm 5 \%$ despite multi-modal therapy highlighting the need for novel therapeutic options [2].

Alterations in the MAP kinase (MAPK) pathway have been implicated in a number of adult and pediatric malignancies [3-5]. The $\mathrm{BRAF}^{\mathrm{V} 600 \mathrm{E}}$ point mutation, an amino acid substitution from valine to glutamic acid at position 600 in BRAF, results in constitutive activation of downstream MEK/ERK. This mutation is commonly detected in malignant melanoma and in $10-15 \%$ of $\mathrm{HGG}$ [5-8].

Clinical trials exploring the use BRAF inhibitors (vemurafenib and dabrafenib) in adults with $\mathrm{BRAF}^{\mathrm{V} 600 \mathrm{E}}$ mutated malignancies have provided valuable information regarding the efficacy and potential side effects of these agents. Large clinical trials of BRAF inhibitors in adults with $\mathrm{BRAF}^{\mathrm{V} 600 \mathrm{E}}$ mutated melanoma resulted in tumor response and prolonged progression free survival (PFS) and OS [9, 10]. Unfortunately, most tumors, including those that initially demonstrated significant response, eventually developed resistance resulting in disease progression after six to eight months $[9,10]$. Resistance of BRAF mutated malignancies to BRAF inhibitors is often due to reactivation of the MAPK pathway [11-13]. In an attempt to overcome this mechanism of resistance, researchers have combined BRAF inhibitors with downstream MEK inhibitors (trametinib) [12-14]. Combination therapy in adults with BRAF mutated melanoma has yielded higher objective response rates, prolonged survival rates, decreased rates of resistance, and decreased incidence of side effects most notably skin toxicities when compared to BRAF inhibitor monotherapy $[9,10,15]$. 
Clinical trials examining the use of BRAF inhibitors alone and in combination with MEK inhibitors in children with $\mathrm{BRAF}^{\mathrm{V} 600 \mathrm{E}}$ mutated malignancies are currently underway. To date, the literature is limited to case reports and series, revealing promising results ranging from partial to complete and sustained responses [16-20]. There are currently no published reports of children with BRAF ${ }^{\mathrm{V} 600 \mathrm{E}}$ mutated malignancies treated upfront with BRAF and MEK inhibitor combination therapy.

In this series, we describe three pediatric patients with $\mathrm{BRAF}^{\mathrm{V} 600 \mathrm{E}}$ mutated $\mathrm{HGG}$ treated with dabrafenib and trametinib. Mutational status was assessed using the OncoScan microarray platform (ThermoFisher), which identifies genome-wide copy number and loss of heterozygosity detection as well as a limited number of frequently tested somatic mutations [21]. One patient received the combination as maintenance therapy, one at the time of disease progression, while the third patient was treated with combination therapy at initial diagnosis.

\section{PATIENT 1}

A 13-year-old male presented with a one-month history of fatigue, emesis and diffuse headache. Computed tomography $(\mathrm{CT})$ and subsequent magnetic resonance imaging $(\mathrm{MRI})$ revealed a $5.9 \times 6.5 \times 6.4 \mathrm{~cm}$ cortically based, heterogeneously enhancing mass involving the left frontal lobe (Figure 1A). He underwent a gross total resection of the tumor (Figure 1B) and pathology was consistent with anaplastic astroblastoma (Figure 1D, 1E). Molecular testing using the OncoScan microarray platform revealed a tetraploid tumor with four copies of all the autosomes, except for chromosome 1, and two copies of each $\mathrm{X}$ and $\mathrm{Y}$. Analysis revealed a $\mathrm{BRAF}^{\mathrm{V} 600 \mathrm{E}}$ mutation and a copy number loss of chromosome 9 encompassing CDKN2A/B.

Following resection, the patient underwent focal radiation therapy (59.4 Gy in 33 fractions) with concurrent temozolomide $\left(90 \mathrm{mg} / \mathrm{m}^{2} /\right.$ day). Post-irradiation, the patient was started on maintenance therapy with dabrafenib (4.5 $\mathrm{mg} / \mathrm{kg} /$ day divided twice daily) and trametinib (2 $\mathrm{mg} /$ day once daily). One month after starting maintenance therapy, he developed mild fatigue. Trametinib was discontinued six months later due to family preference. He had no other treatment-attributable toxicities. The patient remained disease free for 20 months at which time he presented with disseminated disease recurrence and died 2 months later (Figure 1C).

\section{PATIENT 2}

A 12-year-old female presented with a three-week history of diffuse headache and three days of diplopia and blurry vision. Initial head CT demonstrated edema in the
A

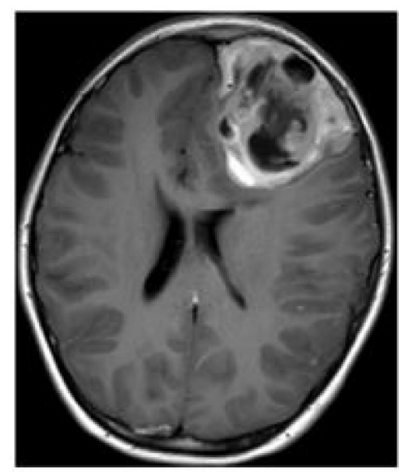

B

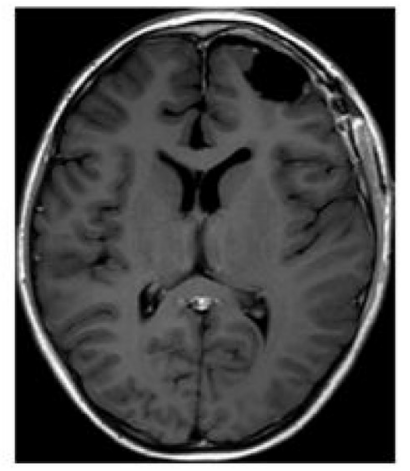

$\mathrm{C}$

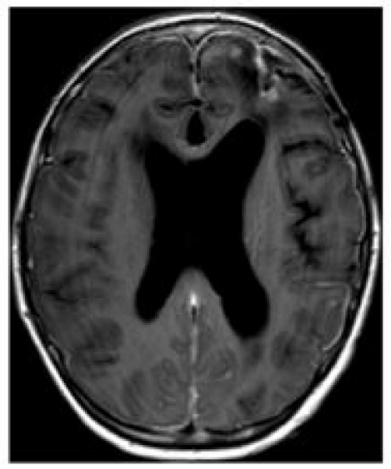

D

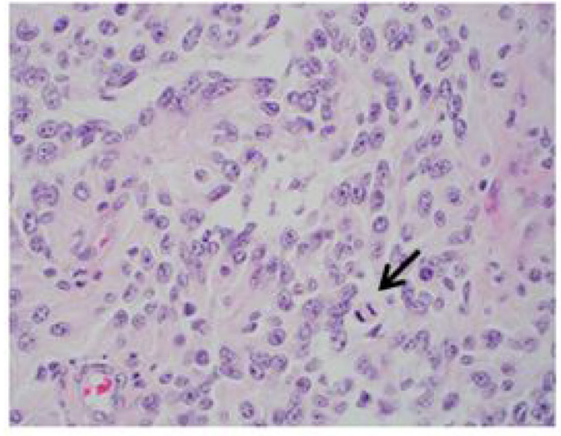

E

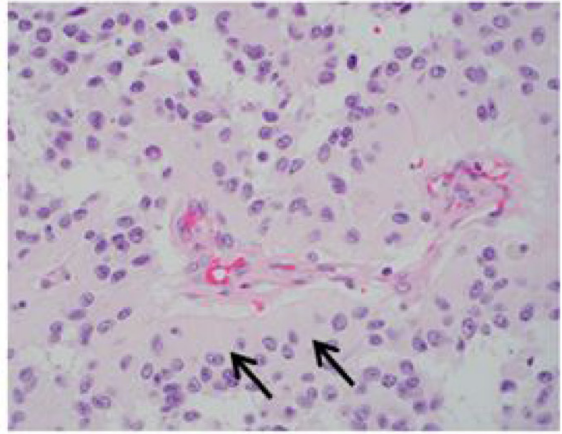

Figure 1: T1-Weighted MRI post gadolinium-based contrast images: (A) at diagnosis, (B) post resection, and (C) at time of recurrence. Histopathologic review of tumor specimen after resection: (D) a moderately to highly cellular neoplasm with scattered mitotic figures (arrow) and a pseudopapillary growth pattern, and (E) pseudorosettes with thick cytoplasmic processes extending towards the vessels (arrows). 
left temporal and frontal lobes. Subsequent MRI revealed a $3.8 \times 2.4 \times 3.1 \mathrm{~cm}$ cortically based mass within the left superior temporal gyrus (Figure $2 \mathrm{~A}$ ).

The patient underwent a gross total resection of the lesion and histopathology was most consistent with an ependymoma. The initial plan was close observation, and MRI performed one month post-operatively demonstrated new infiltrating tumor within the resection cavity (Figure 2B). The patient underwent a partial re-resection (Figure 2E) followed by two cycles of chemotherapy (cisplatin, cyclophosphamide, etoposide, and vincristine). Post-chemotherapy MRI again demonstrated tumor progression requiring additional surgery. Histopathology and immunohistochemistry analysis at the time of the third resection (Figure 2F and 2G) were more consistent with HGG and OncoScan revealed a BRAF ${ }^{\mathrm{V} 600 \mathrm{E}}$ mutation. OncoScan also detected numerous copy number abnormalities including homozygous copy number loss at chromosome 9 involving the $\mathrm{CDKN} 2 \mathrm{~A} / \mathrm{B}$ locus. The patient underwent focal radiation therapy (54 Gy in 30 fractions) with concurrent temozolomide. MRI obtained one-month post chemoradiotherapy again showed tumor progression (Figure 2C). At that time the patient was started on BRAF inhibitor monotherapy (dabrafenib $4.5 \mathrm{mg} / \mathrm{kg} /$ day divided twice daily). MRI performed two months later demonstrated a significant decrease in tumor size (Figure 2D). Six months into treatment with dabrafenib, trametinib was added ( $2 \mathrm{mg} /$ day). She has had no dose-modifying toxicities. The patient has remained on therapy with a small amount of stable disease for 32 months.

\section{PATIENT 3}

A four-year-old female presented after an episode of headache followed by loss of consciousness. On physical exam she was noted to have a left sided visual field deficit. MRI of the brain demonstrated a $6 \times 4.6 \times$ $5 \mathrm{~cm}$ mass centered in the hypothalamus with expansion into the suprasellar area and pons with intratumoral hemorrhage (Figure 3A). The patient underwent a biopsy and ventriculoperitoneal shunt placement. Pathology was consistent with anaplastic ganglioglioma (Figure 3D, 3E) and OncoScan revealed a $\mathrm{BRAF}^{\mathrm{V} 600 \mathrm{E}}$ mutation. In addition to the $\mathrm{BRAF}^{\mathrm{V} 600 \mathrm{E}}$ mutation, a deletion on the short arm of chromosome 4 and numerous copy number alterations spanning chromosome 22 were also discovered. No CDKN2A loss was identified. Given the young age of the child and desire to avoid irradiation, the decision was made to proceed with targeted therapy. The patient was started on dabrafenib $(4.5 \mathrm{mg} / \mathrm{kg} /$ day divided twice daily) upfront with the addition of trametinib (0.025 $\mathrm{mg} / \mathrm{kg} /$ day) one month later. Four weeks after initiation of therapy her visual deficit resolved. MRI obtained three months after initiation of therapy demonstrated an $85 \%$ decrease in tumor size (Figure 3B). MRI performed after eight months of therapy demonstrated a further decrease in size (Figure 3C).
A
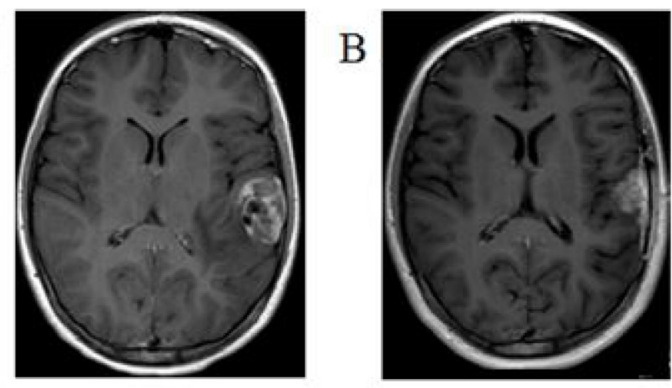

$\mathrm{C}$

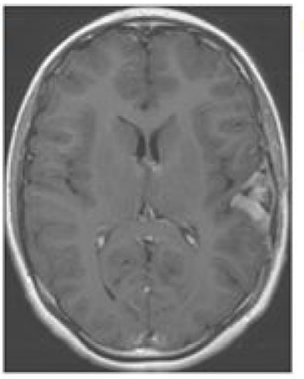

$\mathrm{D}$

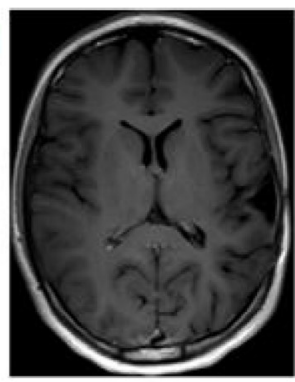

$\mathrm{E}$

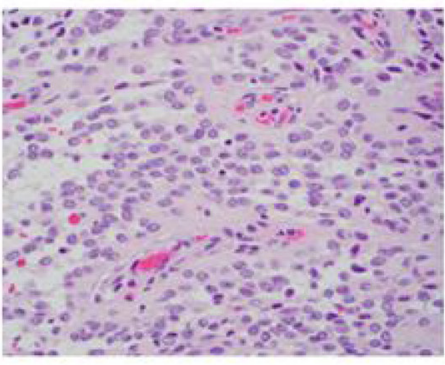

$\mathrm{F}$

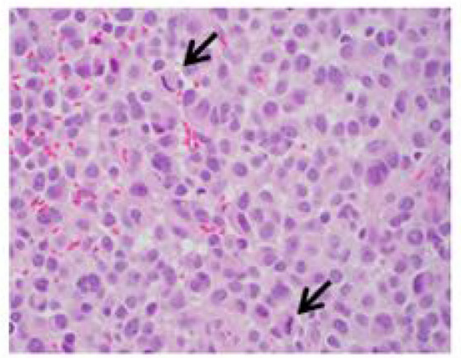

$\mathrm{G}$

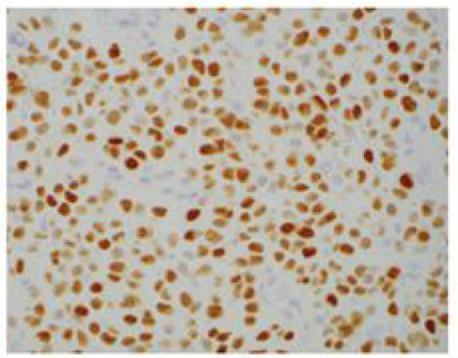

Figure 2: T1-Weighted MRI post gadolinium-based contrast images: (A) at diagnosis, (B) one month post initial resection demonstrating recurrent disease, $(\mathbf{C})$ after third resection and irradiation demonstrating tumor progression (D) after two months of targeted therapy demonstrating tumor response. Histopathologic review of tumor specimen (E) after second resection showing both solid and perivascular growth pattern, (F) after third resection more pronounced epithelioid morphology, moderate nuclear pleomorphism, and increased mitotic activity (arrows), (G) after third resection showing nuclear olig2 expression was strong in tumor cells, consistent with a glioma. 
The patient reports no side effects and has remained on therapy with stable disease for 23 months.

Dermatologic exams and echocardiograms were conducted every three months and ophthalmologic evaluations were completed every three to six months for all patients. None of the patients developed any significant dermatologic, cardiac or ophthalmologic findings.

\section{DISCUSSION}

Despite efforts over the past several decades, survival rates for children with HGG remain dismal [2]. While extent of resection is a major factor in survival, it puts patients at risk for devastating neurologic deficits. Adjuvant therapy is associated with many short and long term effects and offers little survival benefit $[22,23]$. Given the lack of effective therapies for patients with $\mathrm{HGG}$, the use of molecularly targeted agents is of particular interest in the treatment of this disease.

BRAF inhibitor plus MEK inhibitor combination therapy has proved to be effective in the treatment of BRAF mutated malignancies. Investigations of combination therapy in murine models of $\mathrm{BRAF}^{\mathrm{V} 600 \mathrm{E}}$ mutated HGG have demonstrated sustained MAPK pathway inhibition, prolonged survival and decreased cutaneous toxicity when compared to monotherapy [24, 25]. Adults with BRAF mutated melanoma have higher responses rates and prolonged PFS and OS when treated with combination therapy compared to BRAF inhibitor monotherapy $[15,26,27]$. Flaherty et al. reported an overall response rate (ORR) of $76 \%$ in the combination therapy group (dabrafenib and trametinib) compared to $54 \%$ in those receiving monotherapy $(P=0.03)$ while Long et al. reported an ORR of $67 \%$ in subjects receiving combination therapy compared to $51 \%$ in those receiving dabrafenib alone $(P=0.002)$ [15]. Additionally, in a study comparing the combination of dabrafenib and trametinib with vermurafenib monotherapy, Robert et al. reported an ORR of $64 \%$ in the combination group and $51 \%$ in the vemurafenib group $(P<0.001)$ [27].

The efficacy of BRAF inhibitors alone in the treatment of children with recurrent/progressive $\mathrm{BRAF}^{\mathrm{V} 600 \mathrm{E}}$ mutated HGG has been reported [16-20]. Robinson et al. reported a child with a recurrent $\mathrm{BRAF}^{\mathrm{V} 600 \mathrm{E}}$ mutated
A

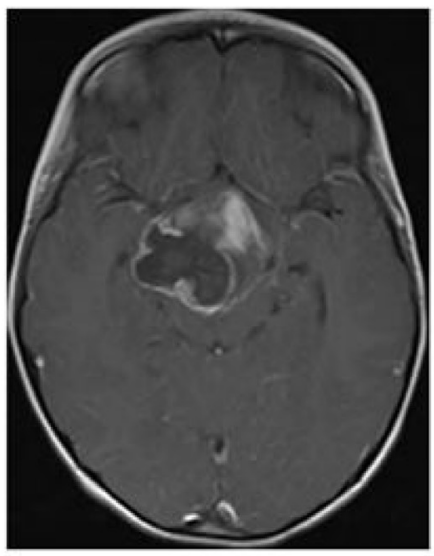

B

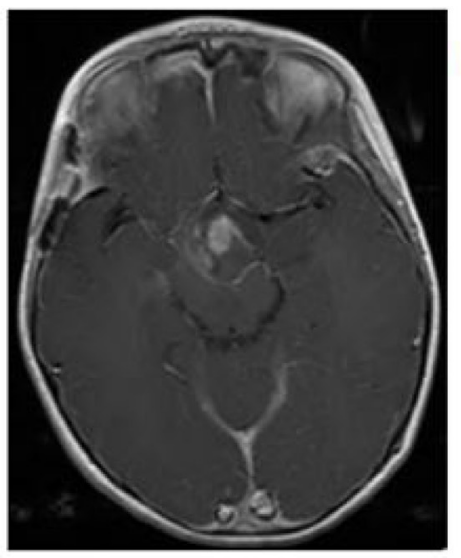

$\mathrm{C}$

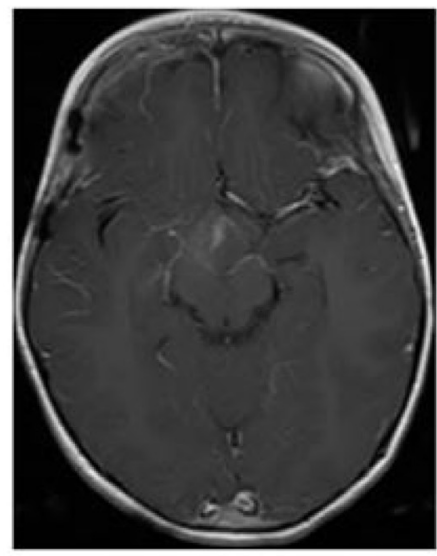

$\mathrm{D}$

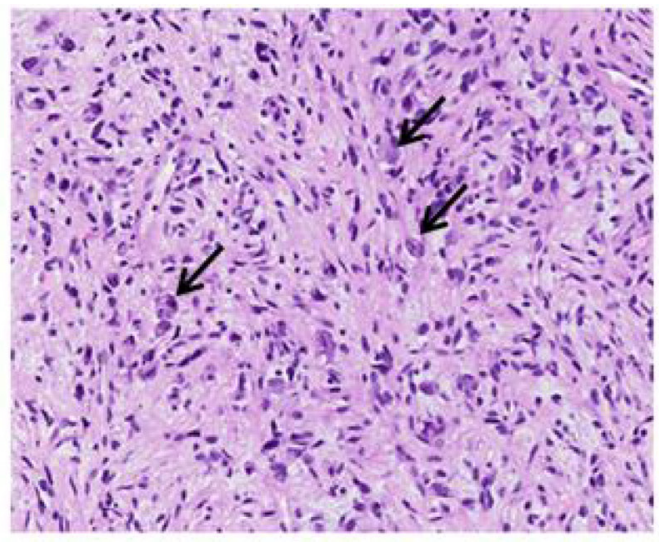

E

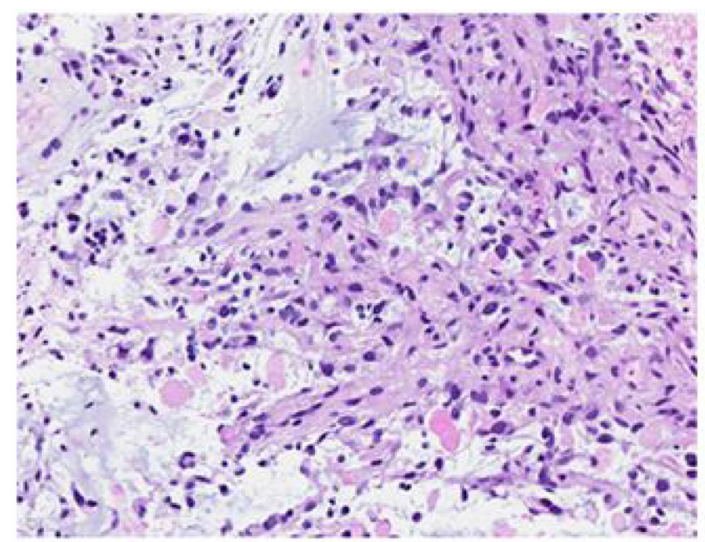

Figure 3: T1-Weighted MRI post gadolinium-based contrast images: (A) at diagnosis, (B) after three months of targeted therapy showing $85 \%$ decrease in tumor size, (C) after eight months of targeted therapy showing a further decrease in tumor size. Histopathologic review of tumor after resection: (D) a moderately cellular tumor with large polygonal ganglion cells (arrows) among smaller, elongated astrocytic cells, (E) frequent mitotic figures and numerous eosinophilic granular bodies. 
glioblastoma multiforme who achieved a complete response after four months of treatment with vemurafenib [16]. A study of dabrafenib monotherapy in children with recurrent/progressive solid tumors has reported the outcomes of eight subjects with HGG: three complete responses, three partial responses and two with disease progression [17]. To date there is one case report of a child treated with combination therapy. Marks, et al. reported a patient with recurrent $\mathrm{BRAF}^{\mathrm{V} 600 \mathrm{E}}$ mutated anaplastic ganglioglioma who demonstrated a complete response to treatment with dabrafenib and trametinib [20].

While BRAF inhibitors have proven effective, their ultimate success may be limited in some patients by the development of resistance. Many mechanisms of resistance have been described, several of which are due to increased RAF dimerization. While BRAF inhibitors sufficiently block signaling by BRAF monomers that are present in $\mathrm{BRAF}^{\mathrm{V} 600 \mathrm{E}}$ mutated cells, they induce RAF dimerization in BRAF wild-type cells [28, 29]. Splice variants of BRAF also demonstrate increased dimerization in the presence of BRAF inhibitors [11]. The ultimate effect of increased dimerization is paradoxical activation of MAPK pathway. Given that reactivation of MAPK pathway activation is a major mechanism of resistance, combination therapy to block downstream MEK is an effective treatment strategy for many patients.

The use of dabrafenib in combination with trametinib in children with newly diagnosed $\mathrm{BRAF}^{\mathrm{V} 600}$ mutated LGG and relapsed/refractory $\mathrm{HGG}$ is currently being investigated (https://clinicaltrials.gov: NCT02684058). Additionally, there are clinical trials under development and in progress examining the use of second generation BRAF inhibitors in children and adults with BRAF mutated malignancies (https://clinicaltrials. gov: NCT03429803, NCT02428712).

However, for the use of BRAF inhibitor monotherapy still raises the concern for development of serious side effects, particularly cutaneous side effects such as rash and squamous cell carcinoma. Studies of the use of combination therapy in adult BRAF mutated melanoma have demonstrated a decreased incidence of cutaneous side effects when compared to BRAF inhibitor monotherapy. Robert et al. reported that cutaneous adverse events were more common in subjects receiving vemurafenib versus those receiving combination therapy including rash ( $43 \%$ vs. $22 \%$ ), photosensitivity reaction ( $22 \%$ vs. $4 \%)$, skin papillomas $(23 \%$ vs. $2 \%)$ and squamous-cell carcinomas and keratoacanthomas (18\% vs. 1\%) [27]. The pediatric patient described by Marks, et al. experienced a morbilliform rash consistent with a Type IV allergic reaction when treated with vemurafenib. When the patient was later treated with a combination of dabrafenib and trametinib, the patient experienced no cutaneous side effects [20].

Here we describe the safe and effective use of combination BRAF and MEK inhibitor therapy in three children with $\mathrm{BRAF}^{\mathrm{V}}{ }^{\mathrm{V}}{ }^{\mathrm{E}} \mathrm{m}$ mutated HGG. We also describe for the first time the use of combination BRAF and MEK inhibitor therapy as an upfront treatment strategy for a pediatric patient. Importantly, all patients tolerated the combination of BRAF and MEK inhibitor therapy well with minimal side effects.

In conclusion, this case series presents evidence that combination BRAF and MEK inhibitor therapy is an effective and appropriate treatment option and that it is safe for children with BRAF ${ }^{\mathrm{V} 600 \mathrm{E}}$ mutated HGG. And although we cannot draw conclusions based on this series, our experience highlights the importance of molecular testing and supports the ongoing development of clinical trials examining the use of combination therapy for children with $\mathrm{BRAF}^{\mathrm{V} 600 \mathrm{E}}$ mutated HGG including those with newly diagnosed disease.

\section{CONFLICTS OF INTEREST}

The authors have no conflicts of interest.

\section{REFERENCES}

1. Ostrom QT, de Blank PM, Kruchko C, Petersen CM, Liao P, Finlay JL, Stearns DS, Wolff JE, Wolinsky Y, Letterio JJ, Barnholtz-Sloan JS. Alex's Lemonade Stand Foundation Infant and Childhood Primary Brain and Central Nervous System Tumors Diagnosed in the United States in 20072011. Neuro Oncol. 2015 (Suppl 10); 16:x1-x36. https://doi. org/10.1093/neuonc/nou327.

2. Cohen KJ, Pollack IF, Zhou T, Buxton A, Holmes EJ, Burger PC, Brat DJ, Rosenblum MK, Hamilton RL, Lavey RS, Heideman RL. Temozolomide in the treatment of highgrade gliomas in children: a report from the Children's Oncology Group. Neuro Oncol. 2011; 13:317-23. https:// doi.org/10.1093/neuonc/noq191.

3. Chen YH, Gutmann DH. The molecular and cell biology of pediatric low-grade gliomas. Oncogene. 2014; 33:2019-26. https://doi.org/10.1038/onc.2013.148.

4. Pfister S, Janzarik WG, Remke M, Ernst A, Werft W, Becker N, Toedt G, Wittmann A, Kratz C, Olbrich H, Ahmadi R, Thieme B, Joos S, et al. BRAF gene duplication constitutes a mechanism of MAPK pathway activation in low-grade astrocytomas. J Clin Invest. 2008; 118:1739-49. https://doi. org/10.1172/JCI33656.

5. Schindler G, Capper D, Meyer J, Janzarik W, Omran H, Herold-Mende C, Schmieder K, Wesseling P, Mawrin C, Hasselblatt M, Louis DN, Korshunov A, Pfister S, et al. Analysis of BRAF V600E mutation in 1,320 nervous system tumors reveals high mutation frequencies in pleomorphic xanthoastrocytoma, ganglioglioma and extracerebellar pilocytic astrocytoma. Acta Neuropathol. 2011; 121:397-405. https://doi.org/10.1007/s00401-011-0802-6.

6. Myung JK, Cho H, Park CK, Kim SK, Lee SH, Park SH. Analysis of the BRAF(V600E) Mutation in Central Nervous System Tumors. Transl Oncol. 2012; 5:430-36. https://doi. org/10.1593/tlo.12328. 
7. Kleinschmidt-DeMasters BK, Aisner DL, Birks DK, Foreman NK. Epithelioid GBMs show a high percentage of BRAF V600E mutation. Am J Surg Pathol. 2013; 37:68598. https://doi.org/10.1097/PAS.0b013e31827f9c5e.

8. Gierke M, Sperveslage J, Schwab D, Beschorner R, Ebinger M, Schuhmann MU, Schittenhelm J. Analysis of IDH1-R132 mutation, BRAF V600 mutation and KIAA1549-BRAF fusion transcript status in central nervous system tumors supports pediatric tumor classification. J Cancer Res Clin Oncol. 2016; 142:89-100. https://doi. org/10.1007/s00432-015-2006-2.

9. Sosman JA, Kim KB, Schuchter L, Gonzalez R, Pavlick AC, Weber JS, McArthur GA, Hutson TE, Moschos SJ, Flaherty KT, Hersey P, Kefford R, Lawrence D, et al. Survival in BRAF V600-mutant advanced melanoma treated with vemurafenib. N Engl J Med. 2012; 366:707-14. https://doi.org/10.1056/NEJMoa1112302.

10. Hauschild A, Grob JJ, Demidov LV, Jouary T, Gutzmer R, Millward M, Rutkowski P, Blank CU, Miller WH Jr, Kaempgen E, Martín-Algarra S, Karaszewska B, Mauch C, et al. Dabrafenib in BRAF-mutated metastatic melanoma: a multicentre, open-label, phase 3 randomised controlled trial. Lancet. 2012; 380:358-65. https://doi.org/10.1016/ S0140-6736(12)60868-X.

11. Poulikakos PI, Persaud Y, Janakiraman M, Kong X, $\mathrm{Ng} \mathrm{C}$, Moriceau G, Shi H, Atefi M, Titz B, Gabay MT, Salton M, Dahlman KB, Tadi M, et al. RAF inhibitor resistance is mediated by dimerization of aberrantly spliced BRAF(V600E). Nature. 2011; 480:387-90. https://doi. org/10.1038/nature10662.

12. Poulikakos PI, Zhang C, Bollag G, Shokat KM, Rosen N. RAF inhibitors transactivate RAF dimers and ERK signalling in cells with wild-type BRAF. Nature. 2010; 464:427-30. https://doi.org/10.1038/nature08902.

13. Hatzivassiliou G, Song K, Yen I, Brandhuber BJ, Anderson DJ, Alvarado R, Ludlam MJ, Stokoe D, Gloor SL, Vigers G, Morales T, Aliagas I, Liu B, et al. RAF inhibitors prime wild-type RAF to activate the MAPK pathway and enhance growth. Nature. 2010; 464:431-35. https://doi.org/10.1038/ nature 08833 .

14. Su F, Viros A, Milagre C, Trunzer K, Bollag G, Spleiss O, Reis-Filho JS, Kong X, Koya RC, Flaherty KT, Chapman PB, Kim MJ, Hayward R, et al. RAS mutations in cutaneous squamous-cell carcinomas in patients treated with BRAF inhibitors. N Engl J Med. 2012; 366:207-15. https://doi. org/10.1056/NEJMoa1105358.

15. Long GV, Stroyakovskiy D, Gogas H, Levchenko E, de Braud F, Larkin J, Garbe C, Jouary T, Hauschild A, Grob JJ, Chiarion Sileni V, Lebbe C, Mandalà M, et al. Combined BRAF and MEK inhibition versus BRAF inhibition alone in melanoma. N Engl J Med. 2014; 371:1877-88. https://doi. org/10.1056/NEJMoa1406037.

16. Robinson GW, Orr BA, Gajjar A. Complete clinical regression of a BRAF V600E-mutant pediatric glioblastoma multiforme after BRAF inhibitor therapy. BMC Cancer. 2014; 14:258. https://doi.org/10.1186/1471-2407-14-258.

17. Kieran MW, Hargrave DR, Cohen KJ, Aerts I, Dunkel IJ, Hummel TR, Jimenez I, Pearson AD, Pratilas CA, Whitlock J, Bouffet E, Shen WP, Broniscer A, et al. Phase 1 study of dabrafenib in pediatric patients (pts) with relapsed or refractory BRAF V600E high- and low-grade gliomas (HGG, LGG), Langerhans cell histiocytosis (LCH), and other solid tumors (OST). J Clin Oncol. 2015 (Suppl 15); 33:10004.

18. Chamberlain MC. Salvage therapy with BRAF inhibitors for recurrent pleomorphic xanthoastrocytoma: a retrospective case series. J Neurooncol. 2013; 114:237-40. https://doi. org/10.1007/s11060-013-1176-5.

19. Bautista F, Paci A, Minard-Colin V, Dufour C, Grill J, Lacroix L, Varlet P, Valteau-Couanet D, Geoerger B. Vemurafenib in pediatric patients with BRAFV600E mutated high-grade gliomas. Pediatr Blood Cancer. 2014; 61:1101-03. https://doi.org/10.1002/pbc.24891.

20. Marks AM, Bindra RS, DiLuna ML, Huttner A, Jairam V, Kahle KT, Kieran MW. Response to the BRAF/MEK inhibitors dabrafenib/trametinib in an adolescent with a BRAF V600E mutated anaplastic ganglioglioma intolerant to vemurafenib. Pediatr Blood Cancer. 2018; 65:e26969. https://doi.org/10.1002/pbc.26969.

21. Foster JM, Oumie A, Togneri FS, Vasques FR, Hau D, Taylor M, Tinkler-Hundal E, Southward K, Medlow P, McGreeghan-Crosby K, Halfpenny I, McMullan DJ, Quirke P, et al. Cross-laboratory validation of the OncoScan ${ }^{\circledR}$ FFPE Assay, a multiplex tool for whole genome tumour profiling. BMC Med Genomics. 2015; 8:5. https://doi.org/10.1186/ s12920-015-0079-z.

22. Sposto R, Ertel IJ, Jenkin RD, Boesel CP, Venes JL, Ortega JA, Evans AE, Wara W, Hammond D. The effectiveness of chemotherapy for treatment of high grade astrocytoma in children: results of a randomized trial. A report from the Childrens Cancer Study Group. J Neurooncol. 1989; 7:16577. https://doi.org/10.1007/BF00165101.

23. Finlay JL, Boyett JM, Yates AJ, Wisoff JH, Milstein JM, Geyer JR, Bertolone SJ, McGuire P, Cherlow JM, Tefft M. Randomized phase III trial in childhood highgrade astrocytoma comparing vincristine, lomustine, and prednisone with the eight-drugs-in-1-day regimen. Childrens Cancer Group. J Clin Oncol. 1995; 13:112-23. https://doi.org/10.1200/JCO.1995.13.1.112.

24. Grossauer S, Koeck K, Murphy NE, Meyers ID, Daynac M, Truffaux N, Truong AY, Nicolaides TP, McMahon M, Berger MS, Phillips JJ, James CD, Petritsch CK. Concurrent MEK targeted therapy prevents MAPK pathway reactivation during BRAFV600E targeted inhibition in a novel syngeneic murine glioma model. Oncotarget. 2016; 7:75839-53. https://doi.org/10.18632/oncotarget.12419.

25. Zhang J, Yao TW, Hashizume R, Hariono S, Barkovich KJ, Fan QW, Prados M, James CD, Weiss WA, Nicolaides 
T. Combined BRAFV600E and MEK blockade for BRAFV600E-mutant gliomas. J Neurooncol. 2017; 131:495-505. https://doi.org/10.1007/s11060-016-2333-4.

26. Flaherty KT, Infante JR, Daud A, Gonzalez R, Kefford RF, Sosman J, Hamid O, Schuchter L, Cebon J, Ibrahim N, Kudchadkar R, Burris HA 3rd, Falchook G, et al. Combined BRAF and MEK inhibition in melanoma with BRAF V600 mutations. N Engl J Med. 2012; 367:1694-703. https://doi. org/10.1056/NEJMoa1210093.

27. Robert C, Karaszewska B, Schachter J, Rutkowski P, Mackiewicz A, Stroiakovski D, Lichinitser M, Dummer R, Grange F, Mortier L, Chiarion-Sileni V, Drucis K, Krajsova I, et al. Improved overall survival in melanoma with combined dabrafenib and trametinib. N Engl J Med. 2015; 372:30-39. https://doi.org/10.1056/NEJMoa1412690.
28. Emery CM, Vijayendran KG, Zipser MC, Sawyer AM, Niu L, Kim JJ, Hatton C, Chopra R, Oberholzer PA, Karpova MB, MacConaill LE, Zhang J, Gray NS, et al. MEK1 mutations confer resistance to MEK and B-RAF inhibition. Proc Natl Acad Sci U S A. 2009; 106:20411-16. https://doi. org/10.1073/pnas.0905833106.

29. Wagle N, Emery C, Berger MF, Davis MJ, Sawyer A, Pochanard P, Kehoe SM, Johannessen CM, Macconaill LE, Hahn WC, Meyerson M, Garraway LA. Dissecting therapeutic resistance to RAF inhibition in melanoma by tumor genomic profiling. J Clin Oncol. 2011; 29:3085-96. https://doi.org/10.1200/JCO.2010.33.2312. 